ческий аспект / С. Г. Карасёва, Е.В.Шкурова, С. И. Шатравский // Вестник Православного Свято-Тихоновского гуманитарного университета. Серия I: Богословие. Философия. Религиоведение. 2017. Вып. 70. С. 85-109.
4. Владыка Филарет на международной конференции в Минске призвал мировое сообщество учиться веротерпимости. URL: https://naviny.by/ rubrics/society/2007/10/26/ic_news_116_279350 (25.03.18).

Viktor R. Iazykovich, Ph. D. in Philosophy. Associate Professo,r Belarusian State University of Culture and Arts (Minsk, Belarus) yazykovich55@mail.ru

\title{
TRADITIONAL RELIGIONS AND CHURCHES IN MODERN BELARUS: LEVEL OF INFLUENCE, AREAS OF ACTIVITIES
}

\begin{abstract}
The article gives the key results of several sociological researches undertook to clear confessional situation in the today's Belarus Republic. Data about a level of Belarussian citizens' involvement into active religious life is outlined. A set of the most powerful religious organizations of the state is named (the leader here is the Belorussian Orthodox Church, exarchate of the Russian Orthodox Church). The main areas of activities of Belarussian religious organizations, such as enlightenment, informational and cultural work, are reviewed; the paper counts major religious projects and measures in education, science, fine art, music, and other spheres. Also, the author stresses out a leading role of the Orthodoxy in construction of moral consciousness, culture and art of Belorussia's people.

Keywords: Belorussian Orthodox Church, Russian Orthodox Church, a language of liturgy, enlightenment, cultural activities, Orthodox culture, a religious identity, Orthodoxy, Catholicism, Islam, Judaism, inter-religious dialogue.

\section{References}

1. Respublika Belarus' $\mathrm{v}$ zerkale sociologii. Sbornik materialov sociologicheskih issledovanij za 2011 god [Republic of Belarus in a Mirror of Sociology. Collection of Writings of Sociological Researches for 2011]. Minsk, 2012. 105 p. [In Russ.].

2. Karasyova, S. G., Shkurova E. V., Shatravskij S. I., Domanskaya A. I., Kazmiruk M. V. Nekotorye oso-bennosti religioznogo naseleniya Belarusi (po materialam issledovaniya «Tipologiya religioznosti $\mathrm{v}$ sovre-mennoj Belarusi», 2012-2015 gg.). [Some Peculiarities of Religious Belorussia's Population (Materials of Research "Typology of Religiousness in the Modern Belorussia", 2012-2015)] // Filosofiya i social'nye

nauki [Philosophy and Social Sciences]. 2016. No. 1. Pp. 82-91. [In Russ.].

3. Karasyova, S. G. Harakteristiki vovlechennosti naseleniya Belarusi v religiyu: mirovozzrencheskij aspekt [Involvement of Belorussia's Population into a Religion: A Worldview Aspect] / S. G. Karasyova, E. V. Shkurova, S. I. Shatravskij // Vestnik Pravoslavnogo Svyato-Tihonovskogo gumanitarnogo universiteta. Seriya I: Bogoslovie. Filosofiya. Religiovedenie.

4. His Grace Filaret Called the World Community to Learn to Religious Tolerance at International Conference in Minsk. URL: https://naviny.by/rubrics/ society/2007/10/26/ic_news_116_279350 (25.03.18). [In Russ.].
\end{abstract}

УДК 130/2(4/5):23/28:304.444

DOI: $10.32340 / 2514-772 X-2019-1-49-57$

О. В. Попова, доктор педагогических наук, профессор, Алтайский государственный гуманитарно-педагогический университет им. В. М. Шукшина (Бийск, Россия) pov@bigpi.biysk.ru

Д. В. Попов, Библиотека информационных образовательных ресурсов «Умней» (Москва, Россия) denissga2015@yandex.ru

\section{ВЗАИМОСВЯЗЬ ЕВРАЗИЙСТВА И ХРИСТИАНСТВА КАК МОДЕЛЬ СОЦИАЛЬНО СПРАВЕДЛИВОГО ОБЩЕСТВА}

Аннотация. Рассмотрена возможность построения социально справедливого общества для современной многонациональной России, в качестве идейного основания которого авторы предлагают рассматривать синтез фундаментальных положений христианского вероучения и взглядов представителей идейно-философского и общественно-политического течения евразийства. Предложена автор- 
ская модель формирования потребностей и возможностей создания социально справедливого общества. При условии сохранения достоинства личности, её духовной свободы возможно успешное решение вопроса о гармонизации одобряемых государством и обществом поведенческих моделей с субъективными взглядами личности на феномен социальной справедливости и индивидуальными представлениями о допустимых с этической точки зрения формах социальной коммуникации.

Ключевые слова: социальная справедливость, социально справедливое общество, идеальное государство, христианство, Царство Небесное, евразийство, утопия, дистопия, антиутопия, духовная деградаџия общества, объективные сочиальные потребности, субъективные социальные потребности.

Человечеству потребна принципиально новая парадигма развития, базирующаяся на идеях равенства, братства, терпимости, толерантности, и наконец, любви в самом широком смысле этого слова. Сейчас на разных уровнях взаимодействия личности и социума от мегадо микроуровней звучит призыв к необходимости создания и реализации модели социально справедливого общества [1, с. 203]. При этом социальная справедливость уже не воспринимается как некая необходимость иметь «всем поровну», «поделить или раздать все всем», «бери что хочешь», «мне в первую очередь» и другие лозунги, мало ассоциирующиеся с общественно значимыми интересами. В данном контексте целесообразно рассмотреть особенности объединения основных положений евразийства и христианства с точки зрения формирования модели социально справедливого общества в такой многонациональной стране как Россия, разместившейся на двух частях света Европе и Азии, едином континенте Евразия.

Евразийство интерпретируется в настоящее время как доминирование культуры над технологией, духовности над потреблением, акцентирует развитие наций в культурнорелигиозном плане с учетом их национального и этнического разнообразия [1, с. 209]. В таких положениях наблюдаются некие социальные противоречия и даже противостояния:

- между насущной необходимостью информатизации, технологизации, цифровизации в целях решения многих промышленных и бытовых проблем и потребностью доминирования духовной культуры, межэтнических толерантных взаимодействий;

- между ростом потребительского спроса преимущественно на материальные блага и сохранением духовно-нравственных традиций;

- между все большим стиранием границ национальной идентичности, этнического разнообразия, вызванным европейской и международной экономической политикой, и куль- турно-религиозными традициями в каждом отдельном государстве;

- между необходимостью проведения единой внутригосударственной социальной политики и духовным-нравственным разнообразием многонациональных стран, таких как Россия.

Евразийство в его классическом виде призвано устранить это противоречие и противостояние. Согласно концепции евразийства, развитие человечества в целом возможно только при условии развития всех составляющих его регионов, этносов, народов, религий и культур в их самобытности и неповторимом своеобразии. Евразийцы выступают за многообразие и против унифицированной усреднённости. Но при этом постулаты евразийства далеки от платоновских утопий, поскольку любая утопия рано или поздно превратится в дистопию, антиутопию [2]. Таковы в общих чертах в настоящее время основные концепции евразийства, которые уже в XIX веке заложили основы представлений о социально справедливом общественном построении для России.

Идея особенности России не нова, но в теории евразийства она несет на себе отпечаток катастрофичности, утраты, падения и в то же время рождения нового в культуре страны. Однако, хотим мы того или нет, наиболее важным при создании модели социально справедливого общества становится учет духовных, нравственных, этических, социальных особенностей. При этом важно учитывать, как сочетаются индивидуальные социальные взгляды с общественно принимаемыми нормами [3, c. 66].

Соотношение целей, потребностей и возможностей создания социально справедливого общества на основе идей евразийства, а также c учетом особенностей многонациональной страны, может быть выражено в виде интегральной модели формирования потребностей и возможностей создания социально справедливого общества, которая представлена структурно-логической схемой на рисунке $1[4$, с. 6$]$. 


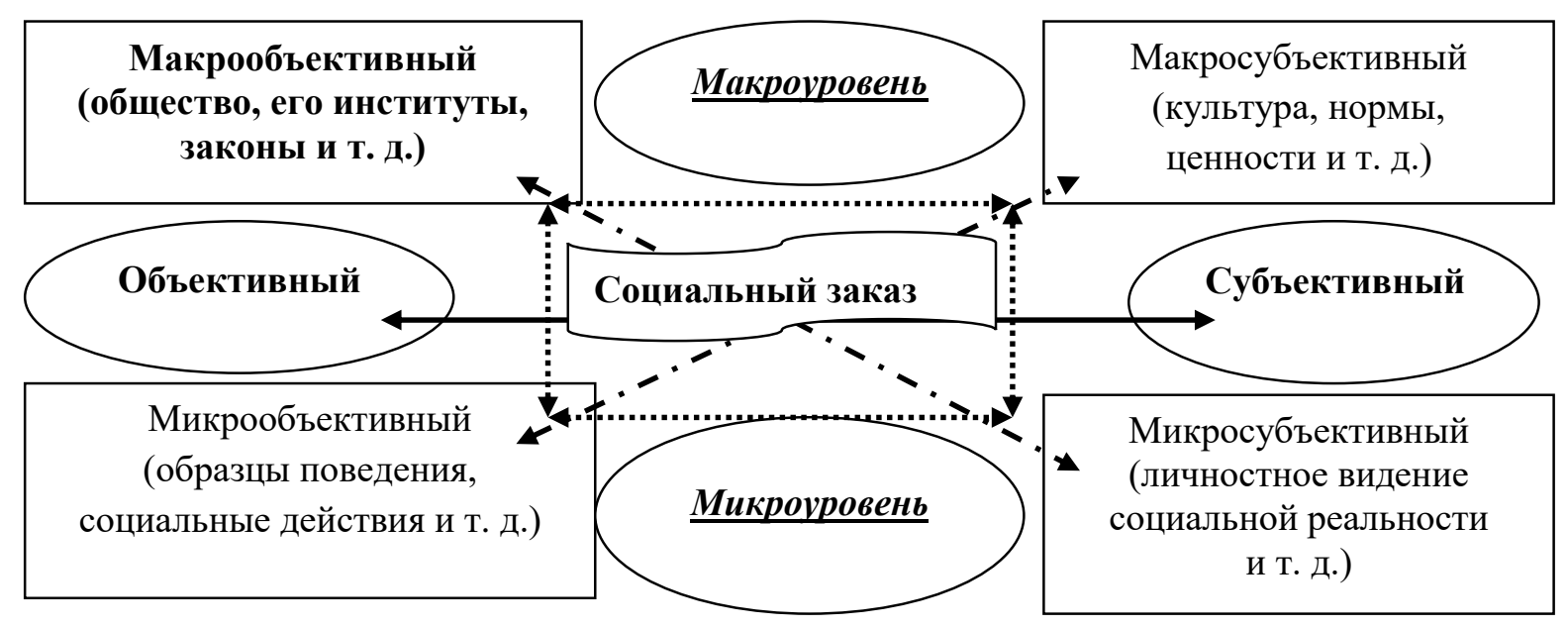

Рис. 1. Интегральная модель формирования потребностей и возможностей создания социально справедливого общества

Из интегральной модели видно, что социальный заказ или «общественный заказ» как общественная потребность, распадается на:

1) макроуровень, уровень требований общества, интегрирующий потребности и возможности создания социально справедливого общества актуальные для общества в целом;

2) микроуровень, интегрирующие потребности и возможности личности, в том числе и в отношении понимания и личного взгляда на социально справедливое общество.

При этом на каждом из уровней присутствуют еще два уровня иерархии и интеграции: объективный уровень и субъективный уровень.

Макроуровень общественных потребностей и возможностей создания социально справедливого общества интегрирует макрообъективные потребности и возможности, которые диктуются и задаются обществом, его институтами, законами, системой сформированности общественного сознания, а также идеями патриотизма, государственности. Макрообъективный уровень задает государственные основы пониманий социальной справедливости и регулирует эти понимания законодательно и экономически [5, с.103].

На макроуровне, как бы не регулировалась общая политика и нормы социальной справедливости, есть интегральные макросубъективные потребности и возможности, которые, исходя из культуры, нормы, ценностей, морали и нравственности каждой личности, создают индивидуальные взгляды на социально справедливое общество. И даже социально благополучная личность, не вступающая в противоречие с государственными и общественными нормами макрообъективных потребностей и возможностей, имеет свое достаточно четко сформулированное представление о социальной справедливости [2-4]. Такие потребности и возможности соединяют макроуровень с микроуровнем интегральной модели создания социально справедливого общества.

Микроуровень также разделяется на микрообъективные и микросубъективные потребности и возможности создания социально справедливого общества. Микрообъективные потребности и возможности создания социально справедливого общества - это общественно установленные и единые в социуме образцы поведения, социальные действия, межличностные взаимодействия, объективно определяемые и регулируемые представления и требования. Микросубъективные потребности и возможности создания социально справедливого общества - это личностное видение социальной реальности, национальноэтнические нормы и правила, принимаемые каждым человеком, личные особенности социальных и общественных взаимодействий $[1, \mathrm{c}$. 208].

Исходя из интегральной модели, мы видим, что в многонациональном, объединяющем самые различные нации и народности государстве, таком как Россия, постоянно возникают потребности в разрешении вышеназванных противоречий, а также некие конфликтные взаимодействия потребностей и возможностей макро- и микроуровней социальной реальности.

Мечта об идеальном месте, идеальном государстве, социально справедливом обществе фактически неосуществима в реалиях присутствия противоречий и противостояний, которые мешают каждому человеку составить 
собственное представление о норме социальной справедливости, которую он ждет от общества и государства [6, с. 73]. Вот тут и появляется потребность найти то идеальное и справедливое, что сделает человека общественно значимым, а общество социально справедливым. Решение этой проблемы - в личной свободе и соответствии представлений о справедливости с их реальным воплощением в жизни. В этом плане идеи евразийства дополняет и расширяет христианство как основа духовности для большинства наций и народностей уже более 2000 лет [6, с. 80].

Христианство в широком смысле слова, если не углубляться в различные религиозные, деноминационные толкования, - это понимание того, что человек сотворен Богом: «И сотворил Бог человека по образу Своему, по образу Божию сотворил его; мужчину и женщину сотворил их» (Быт. 1:27), то есть является личностью, обладающей свободой и творческой способностью. Христианская нравственность исходит из самоценности личности (личность есть «образ Божий» в человеке) и неразрывной связи добра, истинны и свободы: «...И познаете истину, и истина сделает вас свободными» (Ин. 8:32).

Выражая свободу человека, подлинно христианская вера держится не на страхе и внешнем долге, а на любви, направленной к Христу и к каждому человеку как носителю образа Божия: «А теперь прибывает сии три: вера, надежда, любовь; но любовь из них больше» (1Кор. 13:13).

Добро творится человеком на путях применения свободной воли во имя личности и любви: «Кто не любит, тот не познал Бога, потому что Бог есть любовь» (1Ин. 4:8).

Иное применение свободы, свободной воли и пути к справедливости жизни оборачивается самоотрицанием и духовной деградацией человека. В христианстве нравственные нормы обращены не к внешним делам (как это было в язычестве) и не к внешним проявлениям веры (как во многих иных религиозных культурах), а к внутренней мотивации, к некоему внутреннему свободному человеку: «Ибо по внутреннему человеку нахожу удовольствие в законе Божием» (Рим. 7:22). Высшей нравственной инстанцией в христианстве является не долг, стыд и честь, а совесть.

Христианство объясняет, что Царство небесное давно уже существует на земле. Оно живет в каждом добром сердце, в каждом благом поступке, в каждой светлой мысли, независимо от цвета кожи, верования и тем более количества денег в банке. Построить «идеальное государство» или социально справедливое общество без внутренних изменений самого человека, без его духовной свободы, без соотнесения внутренних личностных потребностей и возможностей с потребностями и возможностями других людей и общества в целом проблематично и даже невозможно [6, с. 83].

В основании соотнесения и соединения доктрины евразийства и христианства лежат, на наш взгляд, такие основные идеи:

1. Обеспечение сохранения многонациональности, духовно-нравственного разнообразия и поиск особых путей развития России;

2. Осмысление геоэтнического положения России, критика западной и выработка собственной концепции культуры, нравственности, этики в рамках евразийства;

3. Построение жизни и формирование идеалов общества на христианских началах и вере в Бога;

4. Вера в первичность духовной основы человеческой цивилизации;

5. Утверждение принципов идеократического государства, социально справедливого общества, основанного не на преданиях и придумках, не на материальных интересах, а на сознательных духовных идеях личной свободы;

6. Единомыслие и единение народа в отношении власти (она должна быть правдивой, праведной, логичной, отвечающей менталитету народа), опирающейся на многовековые традиции (вече, земство, казачий круг, дума);

7. Подчинение социальной жизни конкретному идеалу, естественному образованию, вытекающему из народной культуры, христианства, сохраняющему свою стабильность, несмотря на политические, социальные и идеологические изменения, происходящие в обществе.

Точки соприкосновения и единения евразийства и христианства можно разделить на уровни социальных взаимодействий, предлагаемые социальными науками и систематизированные в нашей иерархической модели формирования потребностей и возможностей создания социально справедливого общества. Такие точки соприкосновения необходимо выделять, начиная с мегауровня социализации. В иерархическую модель мегауровень не включен, так как в евразийстве этот уровень практически игнорируется, в христианстве он только среда, незначительно влияющая на духовную свободу. Тем не менее, в объединении евразийства и христианства мегауровень значим, и проигнорировать его мы не имеем права [1]. 
Первый (высший) мегауровень это мировой, межгосударственный уровень. На этом уровне мегасистема может быть представлена как система мирового пространства, с точки зрения евразийства, это некая экобиосоциотехносфера, в которой явное преимущество имеют мегафакторы социальной среды, в той или иной мере через другие группы факторов влияющие на социализацию всех жителей Земли [5, с. 99].

«Евразийцы» считали, что Россию ни в коем случае нельзя рассматривать в качестве некоей культурной провинции Запада: Россия имеет свою Богом данную культуру, а также утверждали, что Россия уже отказалась от идей и идеалов Запада [2, с. 142].

Еще более масштабно на мегауровень смотрит христианство. Библия гласит: «Господь премудростью основал землю, небеса утвердил разумом» (Притч. 3:9).

Библия говорит о глобальном (мега) присутствии Бога: «Он твердыня; совершенны дела Его, и все пути Его праведны; Бог верен, и нет неправды [в Нем]; Он праведен и истинен» (Втор. 32:4).

На мегауровне в истории человечества всегда присутствовала нетерпимость, порождая войны, религиозные преследования, дискриминации, и идеологические противостояния. В повседневной жизни нетерпимость выражалась и выражается в фанатизме, стереотипах, оскорблениях, а в межгосударственном масштабе в дискриминации, преследовании по национальному и религиозному признаку. В данном случае, ни о каких идеалах социальной справедливости не может быть и речи [7, с. 328].

Таким образом, на мегауровне в модели социально справедливого общества правильными становятся идеи евразийства в отделении от мега нетерпимости и соединении с Господним творением Землей на уникальных Богом заложенных основах Любви и Добра [6, с. 77].

Второй уровень рассматриваемой иерархии - это макроуровень, уровень государства, который определяет макросистему социализации личности в социальном пространстве государства в целом. Наибольшее влияние на социализацию личности на этом уровне оказывают макрофакторы социальной среды, о которых мы говорили при описании интегральной модели формирования потребностей и возможностей создания социально справедливого общества.

Из описания видно, что и макрообъективные и макросубьективные взгляды на социально справедливое общество ориентируется на большие социальные общности, системы и группы, а также на изучение достаточно глобальных социальных процессов. Идеи социальной справедливости на данном уровне направлены на постижение и приспособление к законам и закономерностям общественной жизни в целом в совокупности основных общественных, государственных социальных подсистем [2, с. 142].

На мегауровне возникает понятие евразийского государства как государства максимально возможной на мегауровне справедливости. Евразийское государство есть синтез платоновского стремления к абсолюту и христианской близости к нуждам свободного творческого человека. Таким образом, на макроуровне евразийство не представляет социально справедливое общество и даже государство без соединения с духовными основами христианства [6 с. 80].

К сожалению, изучение идей евразийского государства невольно приводит к убеждению, что такое государство подобно монастырю, ведущему некое обособленное соборное хозяйство, а это ничего общего не имеет с христианской свободой и христианской справедливостью. Исследуя Библию как Слово Божие, мы понимаем основные идеи макросвободы и макросправедливости:

1. «Итак, да будет страх Господень на вас: действуйте осмотрительно, ибо нет у Господа Бога нашего неправды, ни лицеприятия, ни мздоимства» (2Пар. 19:7).

2. «Напротив, слава и честь и мир всякому, делающему доброе... Ибо нет лицеприятия у Бога» (Рим. 2:10-11).

3. «Господь творит правду и суд всем обиженным» (Псал. 102:6).

4. «Он (Господь Иисус Христос) сказал им: итак, отдавайте кесарево кесарю, а Божие Богу» (Лук. 20:25).

5. «Когда поселится пришлец в земле вашей, не притесняйте его» (Лев. 19:33).

Это лишь немногие высказывания Библии, которые проливают свет на христианский образ мыслей, на влияние макрофакторов, способствующих изменению взгляда на социально справедливое общество. С точки зрения христианства социально справедливое общество это то, которое направляет и которым управляет Бог [6, с.74].

Исходя из позиций евразийства и особенностей христианства, общегосударственные основы, которые отражают социальные потребности и возможности, формирование которых обеспечивается внешними макрофакто- 
рами, с точки зрения модели социально справедливого общества нам видятся так:

1. Внутригосударственное взаимодействие на макроуровне должно быть с учетом этнических особенностей внутригосударственного социума;

2. Исторически сложившееся общественное устройство, общественно значимые сферы деятельности, система общественных связей и отношений между людьми должна соответствовать христианским нормам построения общества;

3. Влияние географического, ландшафтного расположения и этногеографический статус населения направлен на сохранение среды обитания и обеспечение максимально комфортных условий проживания;

4. Особенности экономических процессов и социально-экономического устройства должны быть непротиворечивыми, базироваться на сохранении самобытности и не должны противопоставлять интересы человека и государства;

5. Внутригосударственное политическое и правовое устройство, устойчивость системы управления, действенность структур власти обеспечивает терпимость и толерантность всех взаимодействий на любом участке общественных отношений.

Третий мезоуровень рассматриваемой иерархии описывает внутригосударственную социальную систему, которая состоит из территориально разобщенных мезосистем социализации личности, соответствующих региональным (территориальным) социальным пространствам (регион, город, село и др.), влияющим на изменение потребностей и возможностей формирования модели социально справедливого общества.

Как славянофилы евразийцы на мезоуровне выступали и выступают с национальных позиций. При этом критикуя космополитически настроенных сторонников Европы, они сделали важный шаг в анализе этнических компонентов русского народа. Оставаясь верными христианству (преимущественно православию), они во многом предвидели политические реалии современной России, то есть укрепление многонационального государства, восстановление христианства (также преимущественно в лице Русской Православной Церкви), возрождение культурных традиций и устоев российского общества [2, с. 142].

Если рассматривать мезоуровень с точки зрения христианства как основы морали и нравственности и отношения к региональным и национальным различиям, то нет разницы между «иудеем и эллином» ибо все христиане, кто исповедует Господа Иисуса Христа [6, c. 82]. На данном уровне мы все в очах Божьих дети Его и Он призывает: «Служите друг другу, каждый тем даром, какой получил, как добрые домостроители многоразличной благодати Божией» (1Пет. 4:10).

Кроме того с точки зрения объединения идей евразийства и христианства мезоуровень - это социальная реальность, где пересекаются происходящие в координатах «интеграция - дифференциация» векторы социальных процессов. Если глобализация - это распространение идей социально справедливого общества как движение сверху вниз, от мега- к микроуровню, то тогда локализация социальных представлений о справедливости общества -это как бы движение снизу вверх от уровня личности к уровню экосферы. Тогда мезоуровень не только способствует осуществлению этого движения, но также преобразует идеи социально справедливого общества, адаптируя глобальные процессы к местным условиям, помогая локальным потребностям и возможностям выйти на макро и даже мегауровни.

Учитывая взаимосвязь идей евразийства и христианства, нам представляется, что наиболее существенными мезофакторами, влияющими на формирование модели социально справедливого общества, являются следующие:

- исторически сложившиеся условия существования человека в конкретном регионе, диктуемые природно-ландшафтным окружением, антропологическими особенностями этнического самосознания, спецификой культуры, языка, религии (мезоэтнос);

- тип и место поселения с присущими ему экологическими, географическими, социальными реалиями;

- особенности и уровень развития коммуникативных средств и каналов, возможности и условия влияния СМИ, внутригосударственные, межгосударственные и международные связи и др.;

- наличие и разнообразие специфических, относительно суверенных зон культуры (субкультуры), отличающихся собственным ценностным строем, обычаями, нормами, например: несколько религий, сект;

- особенности организации и образования семейно-брачных союзов, социальные и демографические особенности и др.

Взаимодействие мезофакторов социальной 
среды обеспечивает развитие и результат процессов социализации в обществе в целом и отдельных личностей в частности, структуру и условия функционирования каждой региональной и (или) территориальной мезосистемы.

Изучив особенности современного евразийства и современного христианства, стремящегося к отсутствию деноминаций, а также обоюдное стремление данных направлений к соединению учения о духовной свободе и социальной справедливости мы считаем во3можным вывести три, на наш взгляд, очевидных и в некотором роде непоколебимых правила:

1. Если речь идет о социально справедливом обществе, то никогда и никакие цели не оправдывают потраченные средства, и не могут стать выше жизни людей.

2. Какие бы задачи не стояли на мега-, макро- и мезо- социальных уровнях достоинство человека неприкосновенно, свободная воля обязательна, духовная свобода решает практически все.

3. В формировании модели социально справедливого общества мега-, макро- и микросоциальные уровни должны исходить из того, что, только представляя общество как целостность, можно понять личность человека.

Опираясь на данные правила, мы понимаем, что огромное значение при формировании модели социально справедливого общества имеет микроуровень, на который приходится исследование социальных процессов, явлений и тенденций, протекающих в относительно небольших социальных системах, таких, как семья, коллектив, малая социальная группа.

С функциональной точки зрения евразийства идеи социально справедливого общества проходят на уровне простейших микросистем [7, с. 329], потребности и возможности личности формируются под влиянием, как минимум, двух групп микрофакторов социальной среды:

- микрофакторы, косвенно влияющие на человека через агентов социализации (родители, друзья, носители национальных и этнических норм и др.);

- микрофакторы прямого воздействия ближайшее окружение, в том числе и простейшие структуры типа «родители»- «дети», «мать»- «отец», «старшие и старейшие члены семейных отношений (деды, прадеды)»«средние (родители) и младшие (дети, внуки, правнуки) члены семейных отношений», «человек»- «носитель материальной и (или) духовной культуры», «личность»- «социальнокультурная среда развития» и др.
Понятие «симфоническая личность»одно из ключевых для понимания евразийства. Оно означает не просто органическое единство многообразия, которое мы показали в двух группах микрофакторов, а такое единство множества, когда единство и множество отдельно друг от друга не существуют и существовать не могут [7, с.330].

Очень близки к концепции такого влияния микроуровня на формирование модели социально справедливого общества идеи христианства, изложенные в Библии [6, с. 83].

Иисус Христос на собственном опыте показал: человеческое достоинство так велико, что Бог может стать Человеком, не унизив Себя. Господь научил нас тому, что нет ничтожных людей, тому, что страдание не может разбить человека, если только он умеет любить. Христос научил нас тому, что в ответ на опустошенность жизни можно ответить, отозвавшись только мольбой к Богу. Больше того, Бог призывает каждого: «Придите ко Мне все труждающиеся и обремененные, и Я успокою вас. Возьмите иго Мое на себя и научитесь от Меня, ибо Я кроток и смирен сердцем, и найдете покой душам вашим» (Мат. 11:28-29).

В Библии есть ответы на все вопросы о том, что есть справедливость и когда человек ощущает себя частью социально справедливого общества: «Ибо заповеди: не прелюбодействуй, не убивай, не кради, не лжесвидетельствуй, не пожелай [чужого] и все другие заключаются в сем слове: люби ближнего твоего, как самого себя» (Рим. 13:9).

Наставления Слова Божия точны и понятны любому человеку от детей до старцев: «О, человек! сказано тебе, что - добро и чего требует от тебя Господь: действовать справедливо, любить дела милосердия и смиренномудренно ходить пред Богом твоим» (Мих. 6:8).

И самое драгоценное из того, что дано христианину, - это «Ибо вот, Царствие Божие внутрь вас есть» (Лук. 17:21).

Да нам уже сейчас путем духовной свободы и следования по путям христианским здесь на Земле гарантировано самое справедливое социальное общество - Царство Божие.

Проведя анализ взаимосвязи евразийства и христианства как модели социально справедливого общества, мы можем сделать следующие выводы:

1. Соединение идей евразийства и христианства позволяет наполнить интегральную модель формирования потребностей и возможностей создания социально справедливого общества конкретным содержанием. 
2. Особенности взаимодействия идей евразийства и христианства позволяют выявить влияние мега-, макро-, мезо- и микроуровней потребностей и возможностей, формирующих представление о социальной справедливости вообще и социально справедливом обществе в частности;

3. Ценность отдельной личности на микроуровне, признаваемая и евразийцами и христианством, делает микроуровень наиболее значимым в формировании представлений о социально-справедливом обществе;

4. Только внутренняя духовная свобода, сохранение достоинства личности могут сформировать состояние проживания в условиях общества социальной справедливости: Царство Божие - самое социально справедливое общество (ср. «Царствие Божие внутрь вас есть» (Лук. 17:21).

5. Несмотря на то, что взаимосвязь идей евразийсва и христианства дает довольно четкие представления о социальной справедливости, наше исследование не носит исчерпывающего характера и требует дальнейшего изучения проблемы формирования модели социально справедливого общества.

Список литературы

1.Маслин, М. А. Классическое евразийство и его современные трансформации. Москва, 2015. $310 \mathrm{c}$.

2. Крылов, М. П. О евразиистве и неоевразиистве // Лабиринт : жур. соц.-гуманит. исследований. 2015. № 1. С. 141-143.

3. Фокин, А. Р. Доктрина божественной простоты: исторические формы и современные дискуссии // Труды кафедры богословия СанктПетербургской Духовной Академии. 2018. № 1. C. $60-96$.

4.Попова, О.В. Особенности универсальной модели в педагогических исследованиях // Методология и практика научных исследований. Бийск, 2017. C. 5-7.

5.Попова, О.В. Персонифицированные информационные технологий в практике социальной работы // Информационные и коммуникационные технологии - 2016. Сочи, 2016. С. 96-112.

6.Колесников, С. А. Современная теология и современная наука: перспективы сотрудничества // Теология. Философия. История. 2018. № 5. C. $73-84$.

7.Лучков, Н.А. К вопросу о формировании личности в условиях трансформации российского социума // Евразийский научный журнал. 2017. № 3. C. 328-331.

Olga V. Popova, Dr. of Pedagogical Sciences, Professor, Vasily Shukshin Altai State Humanities Pedagogical University (Biysk, Russia) pov@bigpi.biysk.ru

Denis V. Popov, Library of Informational Educational Resources "Wise Up" (Moscow, Russia) denissga2015@yandex.ru

\section{INTERRELATION BETWEEN EURASIANISM AND CHRISTIANITY IS A MODEL FOR SOCIALLY FAIR SOCIETY}

Abstract. The paper considers a possibility for construction of a socially fair society for the modern multinational Russia; the authors point out on a synthesis of fundamental principles of Christianity with Eurasianists' views on social and political life as a fit basis for such kind of a society. The authors offer their own model of formation of wants and possibilities for creation of a socially fair society. On the authors' opinion, just in case of keeping a personality's dignity and spiritual freedom it is possible to harmonize, from the one side, behavioral models that approved by a state and a society with, from the other side, a personality's views on social fairness phenomenon and its ideas about ethically acceptable forms of social communication.

Keywords: social fairness, a socially proper society, an ideal state, Christianity, Kingdom of Heaven, Eurasianism, a utopia, a dystopia, an anti-utopia, spiritual decline of a society, objective social needs, subjective social needs.

\section{References}

1. Maslin, M. A. Klassicheskoe evrazijstvo i ego sovremennye transformacii [Classic Eurasian and Its Modern Transformations]. Moscow, 2015. 310 p. [In Russ.].

2. Krylov, M. P. O evraziistve i neoevraziistve [About Eurasianism and Neo-Eurasianism] // Labirint.
Zhurnal social'no-gumanitarnyh issledovanij [Labyrinth. Journal for Social and Humanitarian Studies]. 2015. No. 1. Pp. 141-143. [In Russ.].

3. Fokin, A. P. Doktrina bozhestvennoj prostoty: istoricheskie formy i sovremennye diskussii [Doctrine of Divine Simplicity: Historical Forms and the Today's Discussions] // Trudy kafedry bogoslo-viya Sankt- 
Peterburgskoj Duhovnoj Akademii [Writings of Chair of Theology of the Saint Petersburg Ecclesiastical Academy]. 2018. No. 1. Pp. 60-96. [In Russ.].

4. Popova, O. V. Osobennosti universal'noj modeli v pedagogicheskih issledovaniyah // [Peculiarities of a Universal Model in Pedagogical Studies] // Metodologiya i praktika nauchnyh issledovanij [Methodology and Practice of Scientific Researches]. Biysk, 2017. Pp. 5-7. [In Russ.].

5. Popova, $O$. V. Personificirovannye informacionnye tekhnologij $\mathrm{v}$ praktike social'noj raboty [Information and Communication Technologies] // Informacionnye i kommunikacionnye tekhnologii 2016 [Information and Communication Technology] Информационные и коммуникационные техноло- гии - 2016. Sochi, 2016. Pp. 96-112. [In Russ.].

6. Kolesnikov, S. A. Sovremennaya teologiya i sovremennaya nauka: perspektivy sotrudnichestva [Today's Theology and Modern Science: Perspectives of Cooperation] // Teologiya. Filosofiya. Istoriya [Theology. Philosophy. History]. 2018. No. 5. Pp. 73-84. [In Russ.].

7. Luchkov, N. A. К вопросу о формировании личности в условиях трансформации российского социума $\mathrm{K}$ voprosu o formirovanii lichnosti $\mathrm{v}$ usloviyah transformacii rossijskogo sociuma [On Construction of a Personality in Context of Transformation of Russian Society] // Evrazijskij nauchnyj zhurnal [Eurasian Scientific Journal]. 2017. № 3. Pp. 328-331. 